\title{
Bio-based polyricinoleate and polyhydroxystearate: properties and evaluation as viscosity modifiers for lubricants
}

\author{
Hélène Méheust, Jean-François Le Meins, Etienne Grau*, Henri Cramail* \\ Henri.Cramail@enscbp.fr \\ egrau@enscbp.fr
}

Number of pages: 13

Number of Figures: 11

Number of Tables: 2

Figure SI - 1: ${ }^{1} \mathrm{H}$ NMR spectra of (1) methyl-12- hydroxystearate monomer and

(2)polyhydroxystearate in $\mathrm{CDCl}_{3}$

Figure $\mathrm{SI}-2:{ }^{1} \mathrm{H}$ NMR spectra polyricinoleate in $\mathrm{CDCl}_{3}$

Figure $\mathrm{SI}-3:{ }^{1} \mathrm{H}$ NMR spectra of polyhydroxystearate in $\mathrm{CDCl}_{3}$

Figure SI - 4: SEC traces of (1)Polyricinoleate and (2) Polyhydroxystearate. Measurement performed in THF.

Figure SI - 5: PRic glass transition temperature as a function of (1) PRic molar mass $\left(M_{n}\right)$ and (2) $1 / M_{n}$

Figure SI - 6: Translation factor as a function of $1 /$ T according to Andrade law

Figure SI - 7: Complex viscosity as a function of shear strain for a series of PRic with various $\mathrm{M}_{\mathrm{w}}$. Performed at $20^{\circ} \mathrm{C}$ with an angular frequency of $10 \mathrm{rad}_{\mathrm{s}} \mathrm{s}^{-1}$

Figure SI - 8: Master curves at $-20^{\circ} \mathrm{C}$ of PRic samples. Reduced storage and loss modulus are expressed versus the reduced angular frequency

Figure SI - 9: Polyricinoleate reduced complex viscosity versus the reduced angular frequency obtained from $\mathrm{TTS}$ at $-20^{\circ} \mathrm{C}$ as reference temperature, $1 \%$ shear strain

Figure SI -10: Viscosity versus shear rate obtained by creep measurements. (1) PRic-7 performed at $20^{\circ} \mathrm{C}$, (2) PRic-9 performed at $200^{\circ} \mathrm{C}$ and (3) PRic-10 performed at $150^{\circ} \mathrm{C}$ 
Figure SI-11: Master curves at $80^{\circ} \mathrm{C}$ of PRic- 9 and PRic- 10 samples. Reduced storage and loss modulus are expressed versus the reduced angular frequency

Table SI-1: Translation factor and actovation energy obtained by TTS master curves at $-20^{\circ} \mathrm{C}$.

Table SI-2: Translation factor and activation energy obtained by TTS master curves at $80^{\circ} \mathrm{C}$ as reference. 


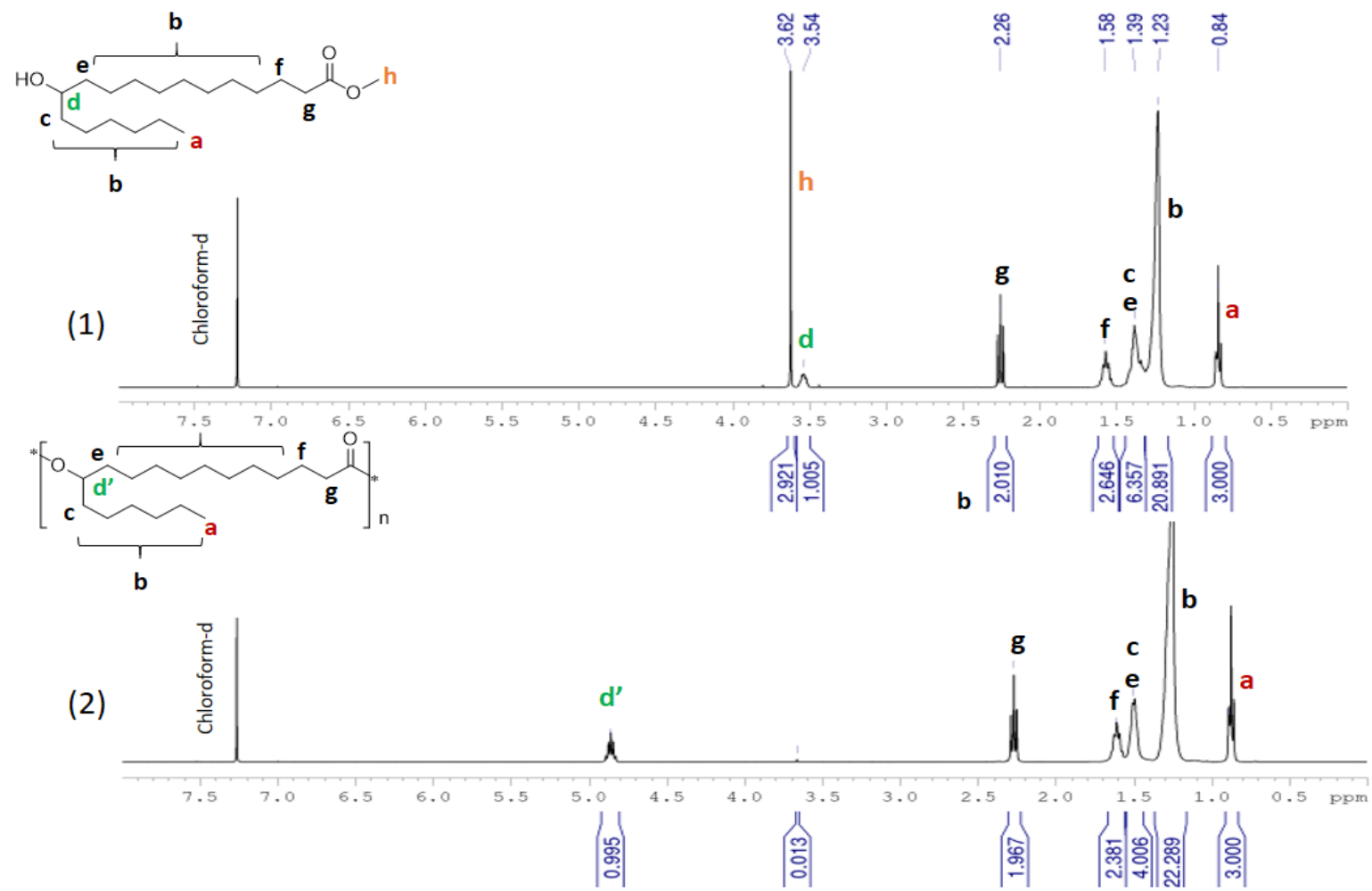

Figure SI - 2: ${ }^{1} \mathrm{H}$ NMR spectra of (1) methyl-12- hydroxystearate monomer and (2)polyhydroxystearate in $\mathrm{CDCl}_{3}$ 


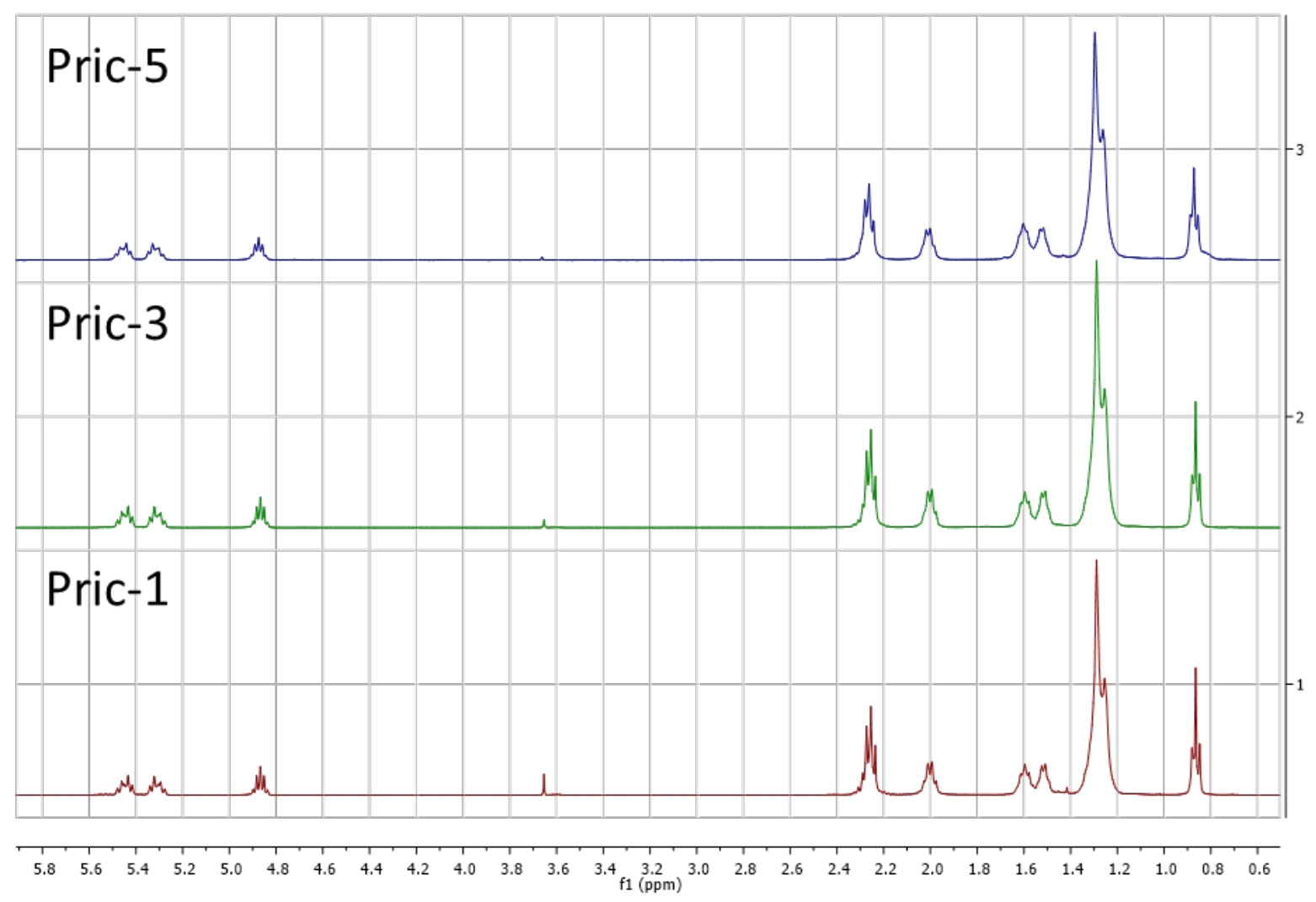

Fig SI - 2: ${ }^{1} \mathrm{H}$ NMR spectra of polyricinoleate in $\mathrm{CDCl}_{3}$

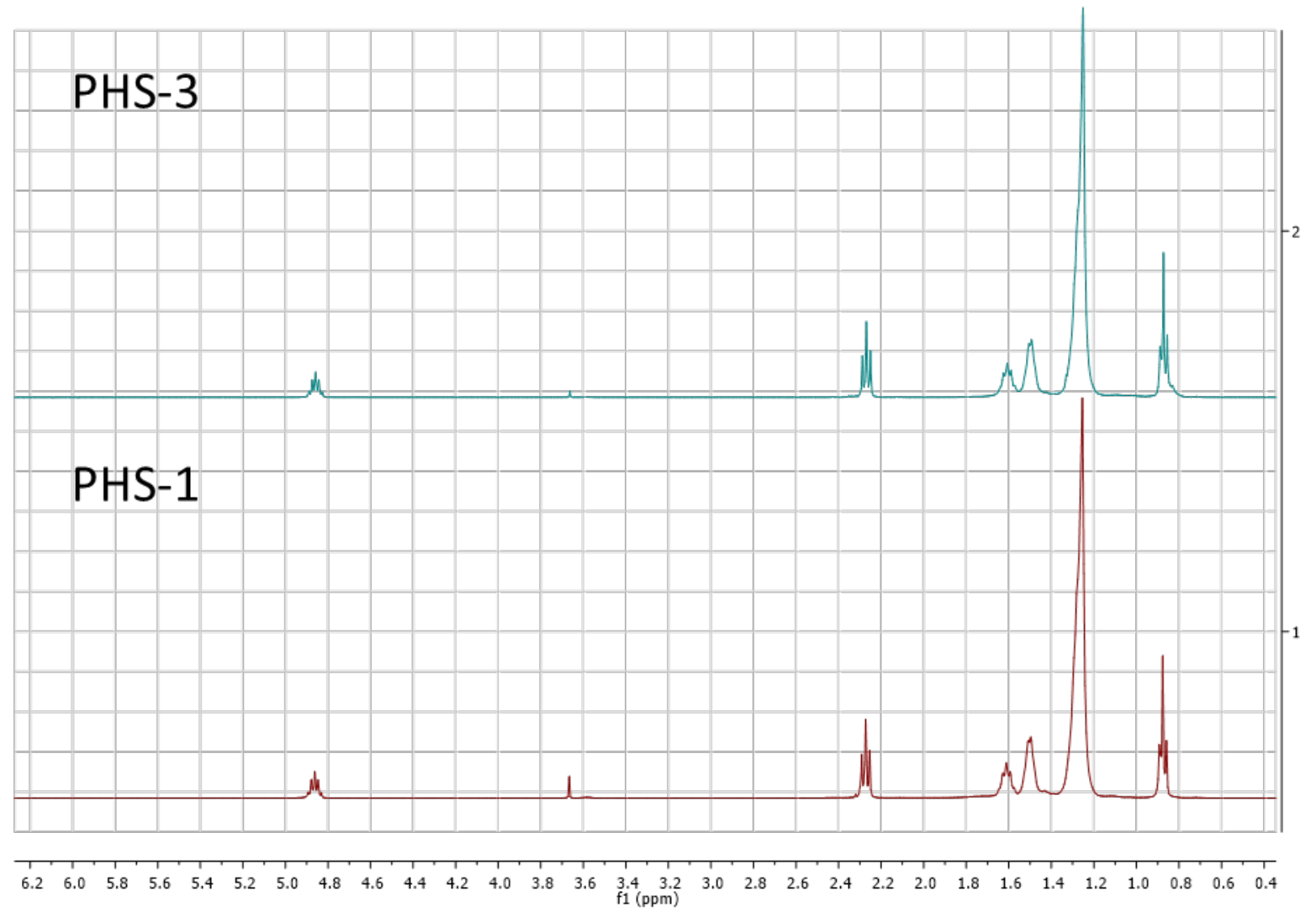

Figure $\mathrm{SI}-3:{ }^{1} \mathrm{H}$ NMR spectra of polyhydroxystearate in $\mathrm{CDCl}_{3}$ 

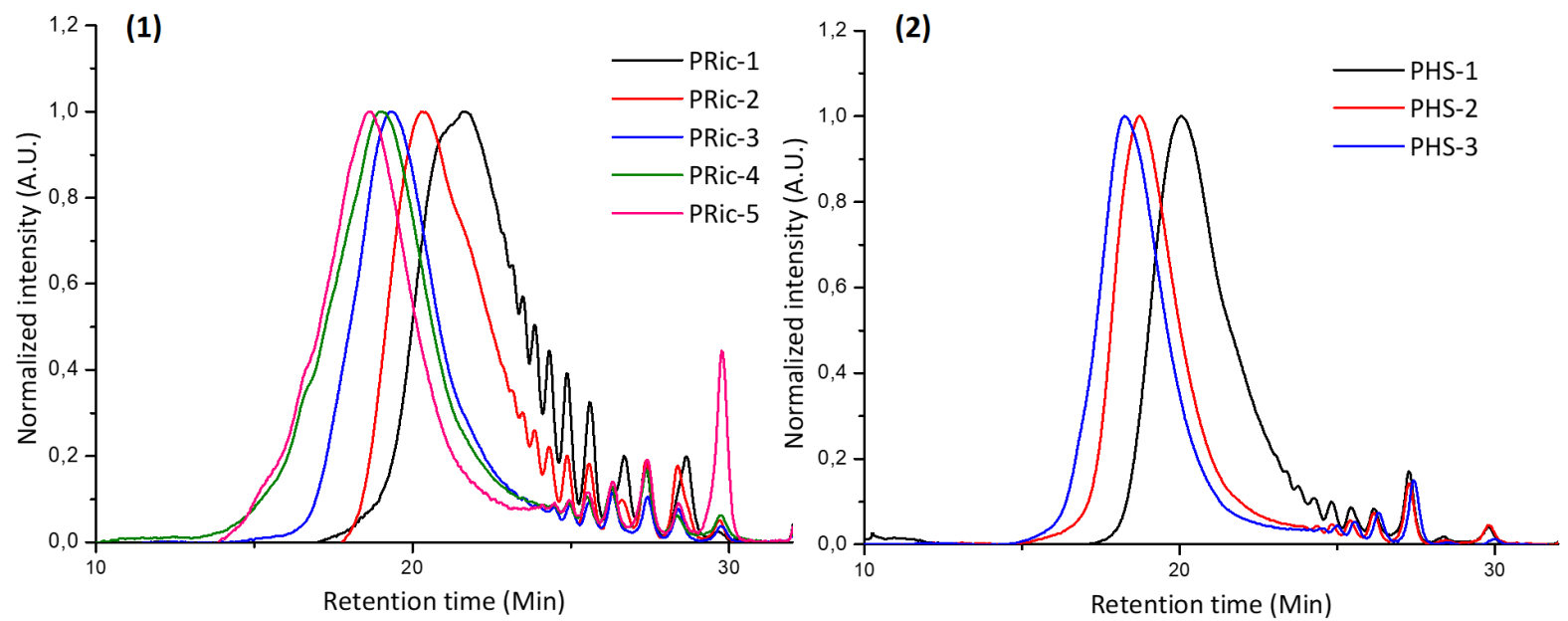

Figure SI - 4: SEC traces of (1)Polyricinoleate and (2) Polyhydroxystearate. Measurement performed in THF.
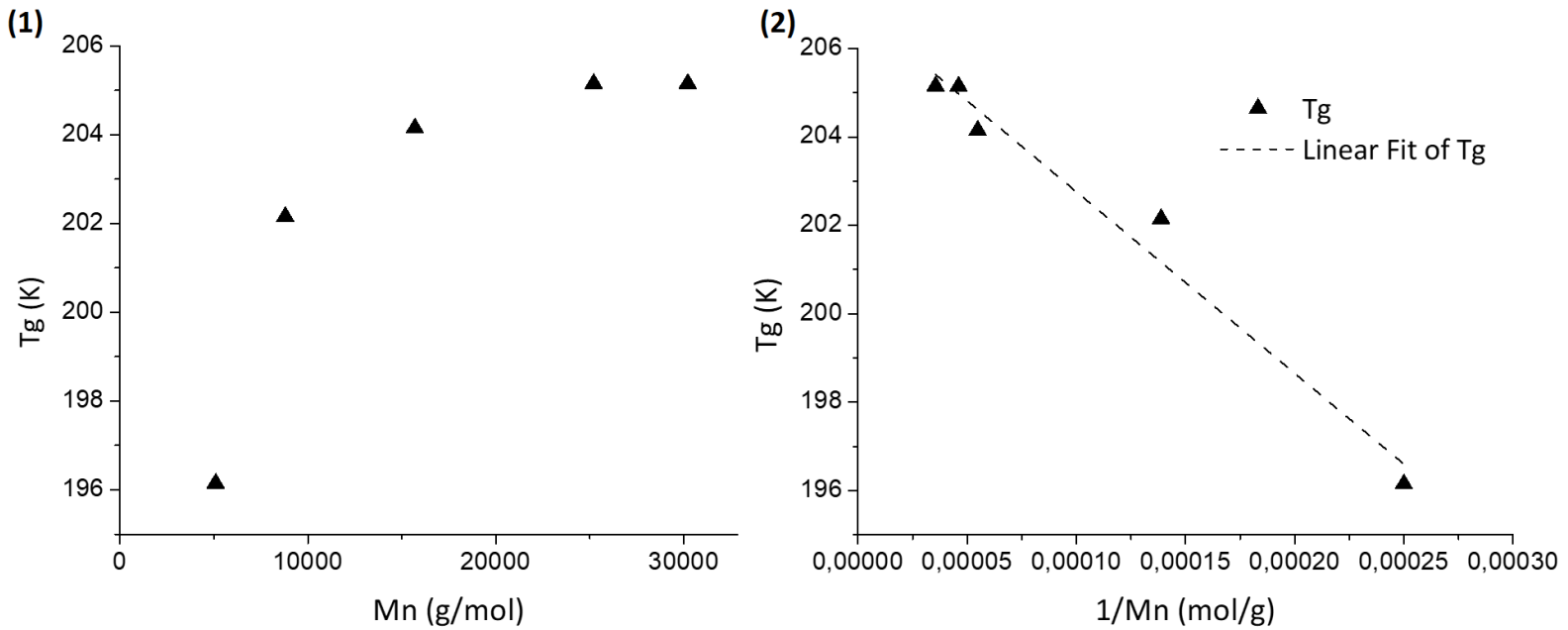

Figure SI - 5: PRic glass transition temperature as a function of (1) PRic molecular weight $\left(\mathrm{M}_{\mathrm{n}}\right)$ and (2) $1 / \mathrm{M}_{\mathrm{n}}$ 


\section{$\underline{\text { Rheometry analysis: }}$}

\section{Methodology}

The objective was to establish the evolution profile of the newtonian viscosity versus molecular weight of the different system at a fixed, reference temperature. Viscosity was estimated through the evaluation of complex viscosity $\eta^{*}$ measured at different temperature, and the establishment of master curves through the use of the Time Temperature Superposition (TTS).

The complex viscosity was calculated with the data obtained from the dynamic shear measurements according to equation $1 .^{1}$

$$
\left|\eta^{*}\right|=\frac{\left|G^{*}\right|}{\omega}=\frac{\sqrt{\left(G^{\prime}\right)^{2}+\left(G^{\prime \prime}\right)^{2}}}{\omega} \quad \text { Eq.1 }
$$

where the elastic modulus G' and the loss modulus G'" are given as a function of the angular frequency $\omega$.

According to Cox-Merz Rule, ${ }^{1}$ the dependence of the steady shear viscosity on the shear rate is equal to the dependence of the complex viscosity as a function of frequency. Therefore a plateau of complex viscosity at low angular frequencies reflects the Newtonian viscosity. In some cases, when the plateau value of complex viscosity could not be obtained with the master curves, creep experiments have then been performed to measure the viscosity.

The shift factor $\mathrm{a}_{\mathrm{T}} /$ Tref used to establish master curves follows an Andrade law ${ }^{1}$ according to Equation 2, as illustrated in the Figure SI 6

$$
\ln \left(a_{T}\right)=\frac{E_{a}}{R}\left(\frac{1}{T}-\frac{1}{T_{R e f}}\right) \quad \text { Eq. } 2
$$

where $E_{a}$ is the activation energy and $R$ the universal gas constant. By using Andrade law, it is possible to determine the viscosity of the material at another temperature, as, the translation factor $a_{T}$ is correlated to the melt polymer viscosity. ${ }^{2}$ and can be considered as the ratio of viscosity at two different temperature (eq 3 ).

$$
a_{T}=\frac{\eta_{T}}{\eta_{T_{R e f}}} \text { Eq.3 }
$$

Then, the Newtonianviscosities could be estimated at $20^{\circ} \mathrm{C}$ for all the polymers.. 


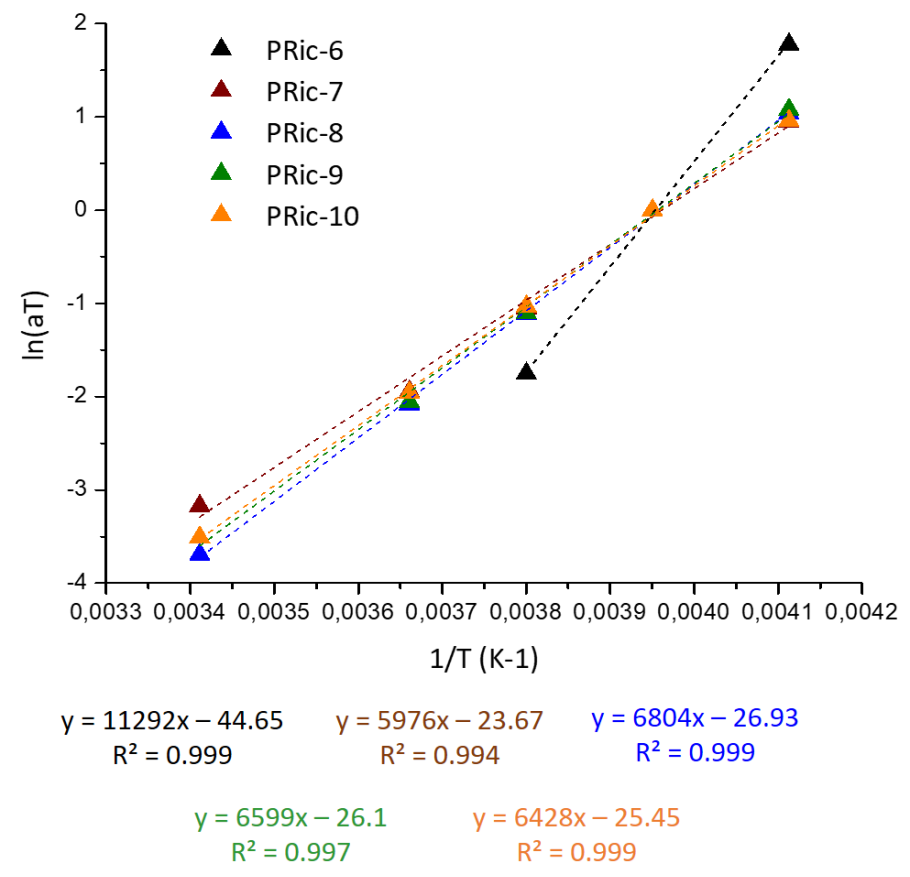

Figure SI - 6: Translation factor as a function of $1 / T$ fitted with Andrade law

\section{Rheology results}

As displayed in Figure SI-7, first the linear domains of PRic with different molecular weights were determined. For all samples, a linear domain was obtained up to a shear strain of $100 \%$. A shear strain of $\gamma=1 \%$ was fixed for the frequency sweep experiments.

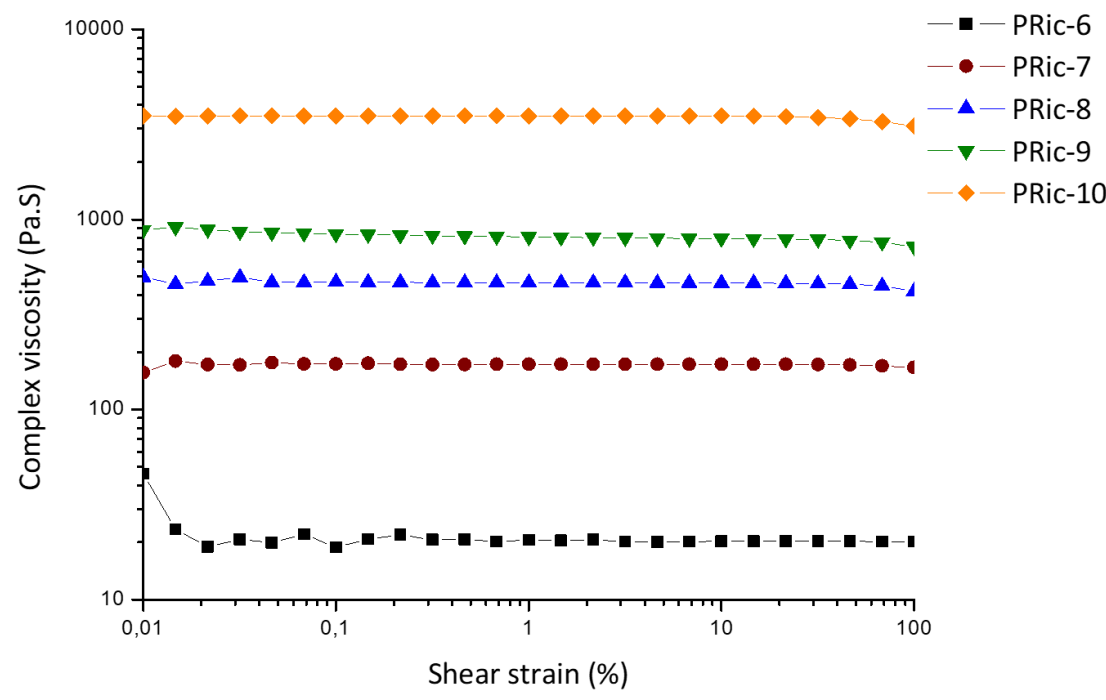

Figure SI - 7: Complex viscosity as a function of shear strain for a series of PRic with various $\mathrm{M}_{\mathrm{w}}$. Performed at $20^{\circ} \mathrm{C}$ with an angular frequency of $10 \mathrm{rad} . \mathrm{s}^{-1}$ 
The rheological properties were evaluated under dynamic frequency sweep (100 rad.s ${ }^{-1}-0.1$ rad. $\mathrm{s}^{-1}$ ) at different temperature and the time-temperature superposition (TTS) principle was applied. The master curves of elastic and loss moduli obtained for a reference temperature of $20{ }^{\circ} \mathrm{C}$ are plotted in Figure SI-8 

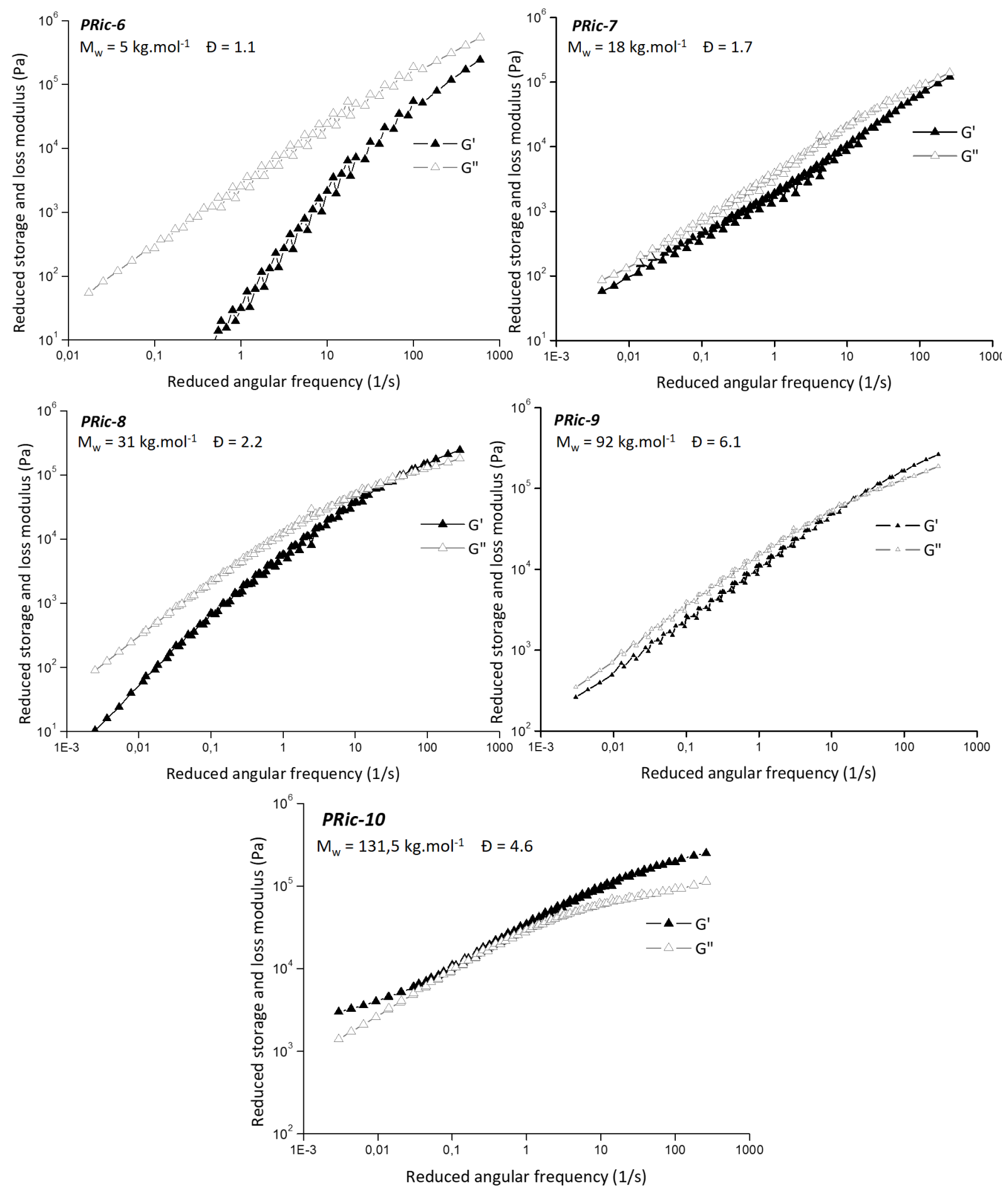

Figure $\mathrm{SI}$ - 8: Master curves at $-20^{\circ} \mathrm{C}$ of PRic samples. storage and loss modulus are expressed versus the reduced angular frequency

From these data, the complex viscosity of the series of PRics were expressed as a function of angular frequency, with $0,003<\omega<294$ rad. $\mathrm{s}^{-1}$ at $-20^{\circ} \mathrm{C}$. Results are plotted in Figure SI-9. 


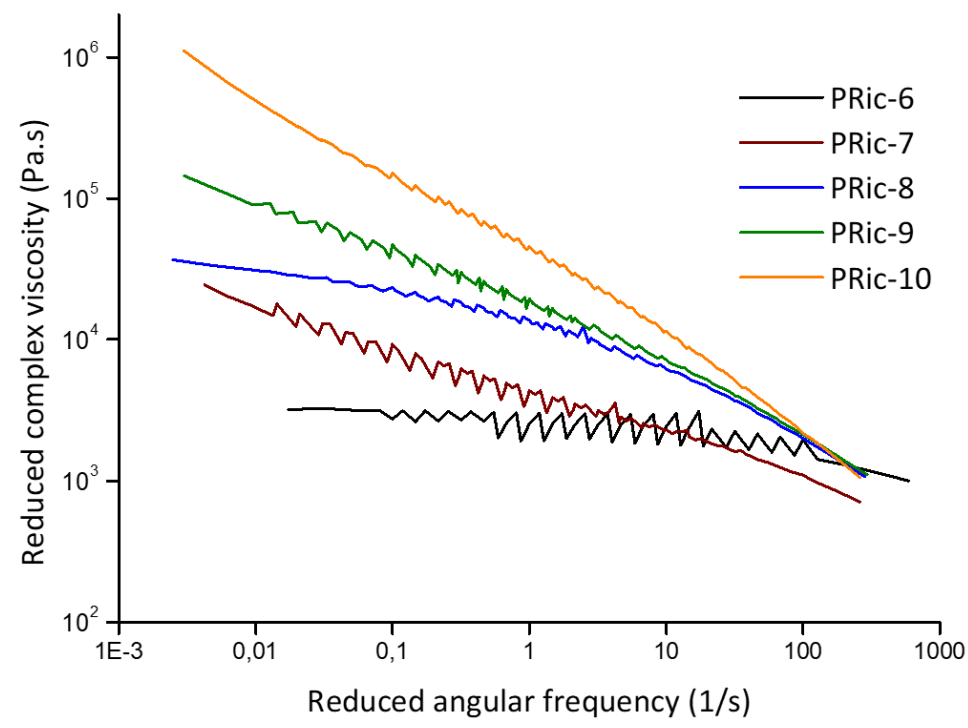

Figure SI - 9: Polyricinoleate reduced complex viscosity versus the reduced angular frequency obtained from TTS at $-20^{\circ} \mathrm{C}$ as reference temperature, $1 \%$ shear strain

Regarding the master curves in Figure SI-8, it appears clearly that for most of the polyricinoleate tested, no viscosity plateau is observed at low frequencies, with the noticeable exceptions of PRic-6 and PRic-8. In these two cases, viscosity plateau is observed for $\omega<1$ rad. $\mathrm{s}^{-1}$ in the case of PRic- 6 and $\omega<0.1$ rad.s $\mathrm{s}^{-1}$ in the case of PRic- 8 allowing determination of a Newtonian viscosity at $-20^{\circ} \mathrm{C}$

$$
\begin{aligned}
& \text { PRic-6: } \eta^{*}-20{ }^{\circ} \mathrm{C}=3010 \pm 230 \text { Pa s } \\
& \text { PRic-8: } \eta^{*}-20{ }^{\circ} \mathrm{C}=34900 \pm 1500 \mathrm{~Pa} \mathrm{~S}
\end{aligned}
$$

Then the viscosity could be calculated at $20^{\circ} \mathrm{C}$ using Andrade law.

For the other PRic samples, the viscosity was not stable with the frequency in the range of frequencies and temperatures tested. Newtonian viscosities were then determined using creep experiments in which several shear stress were applied on the polymer sample and the resulting shear strain was measured as a function of time. Different temperatures were used for each creep experiments, a viscosity and steady state shear rate value were reported. Viscosity obtained was plotted versus the shear rate as displayed in Figure SI-10. The obtained viscosities were almost independent of the the shear rate and thus considered as Newtonian, Although a beginning of shear thinning is detected in Pric-10

PRic-7: $\eta_{20}{ }^{\circ} \mathrm{C}=28.80 \pm 0.03 \mathrm{~Pa} . \mathrm{s}$ 


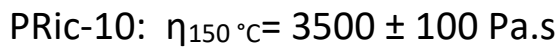

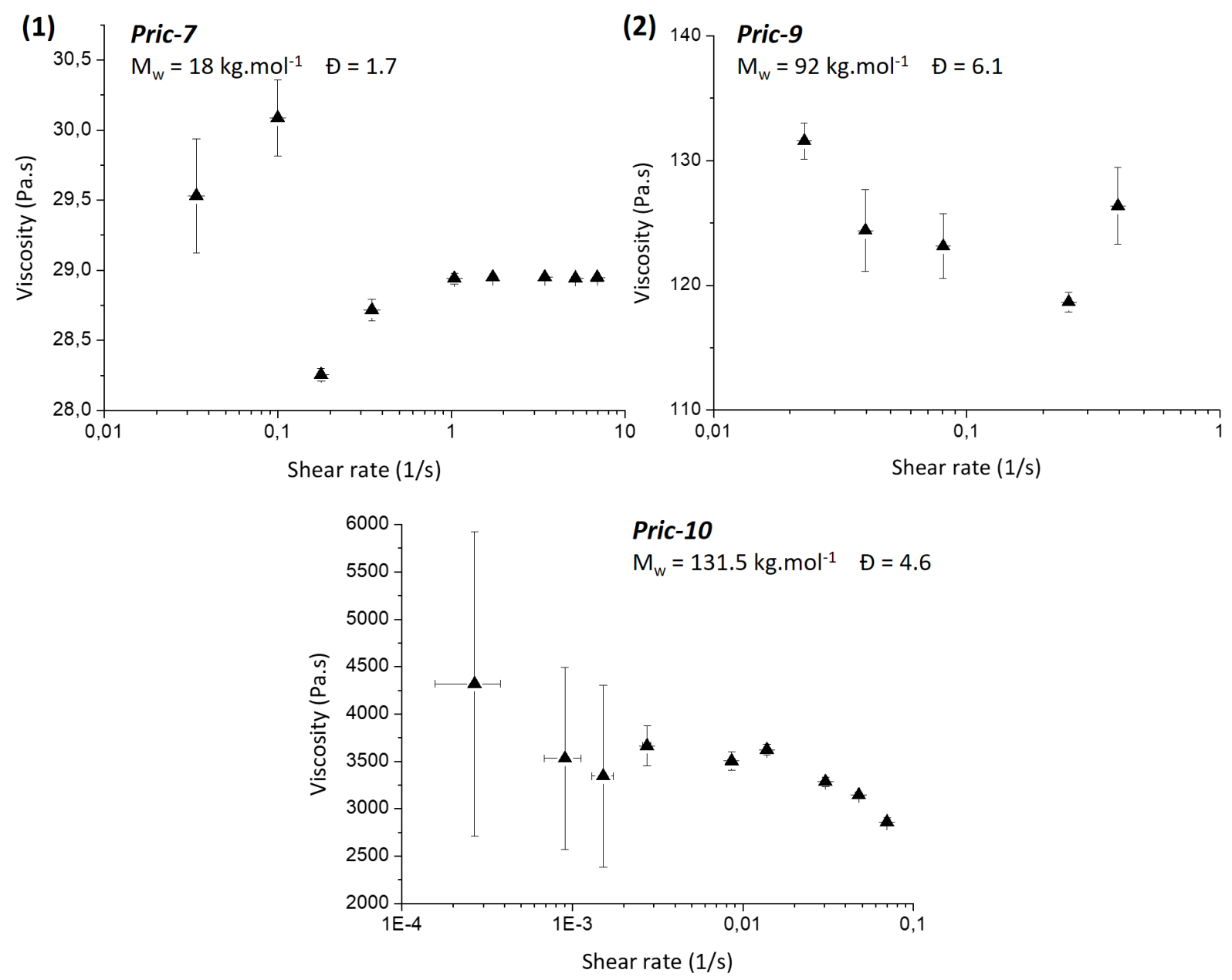

Figure SI - 10: Viscosity versus shear rate obtained by creep measurements. (1) PRic-7 performed at $20^{\circ} \mathrm{C}$, (2) PRic-9 performed at $200^{\circ} \mathrm{C}$ and (3) PRic-10 performed at $150{ }^{\circ} \mathrm{C}$

For Pric 8 and Pric 6, the Newtonian viscosity at $20^{\circ} \mathrm{C}$ were calculated from the value of Newtonian viscosity obtained with master curves of complex viscosity versus frequency at a temperature reference of $-20^{\circ} \mathrm{C}$. for Pric -7 , Pric 9 and Pric 10 Newtonian viscosities were obtained by creep experiments, as they could not be determined through dynamic experiments.. As the temperature chosen for creep experiments of Pric 9 and Pric $10\left(200^{\circ} \mathrm{C}\right.$ and $150^{\circ} \mathrm{C}$ respectively ) were far above the reference temperature of $-20^{\circ} \mathrm{C}$, another master curve $\left(\mathrm{G}^{\prime}, \mathrm{G}^{\prime}\right.$, $\mathrm{f}(\mathrm{aTw})$ have been realized for Pric-9 and Pric-10 at a reference temperature of $80^{\circ} \mathrm{C}$ and new shift factor aT has been calculated. Again these shift factor obey an Andrade law but slight variation of activation energy compared to the reference temperature of $-20^{\circ} \mathrm{C}$ was obtained 
(Table SI-2). We used this activation energy for PRic 9 and Pric 10 to calculate the Newtonian viscosity at $20^{\circ} \mathrm{C}$.
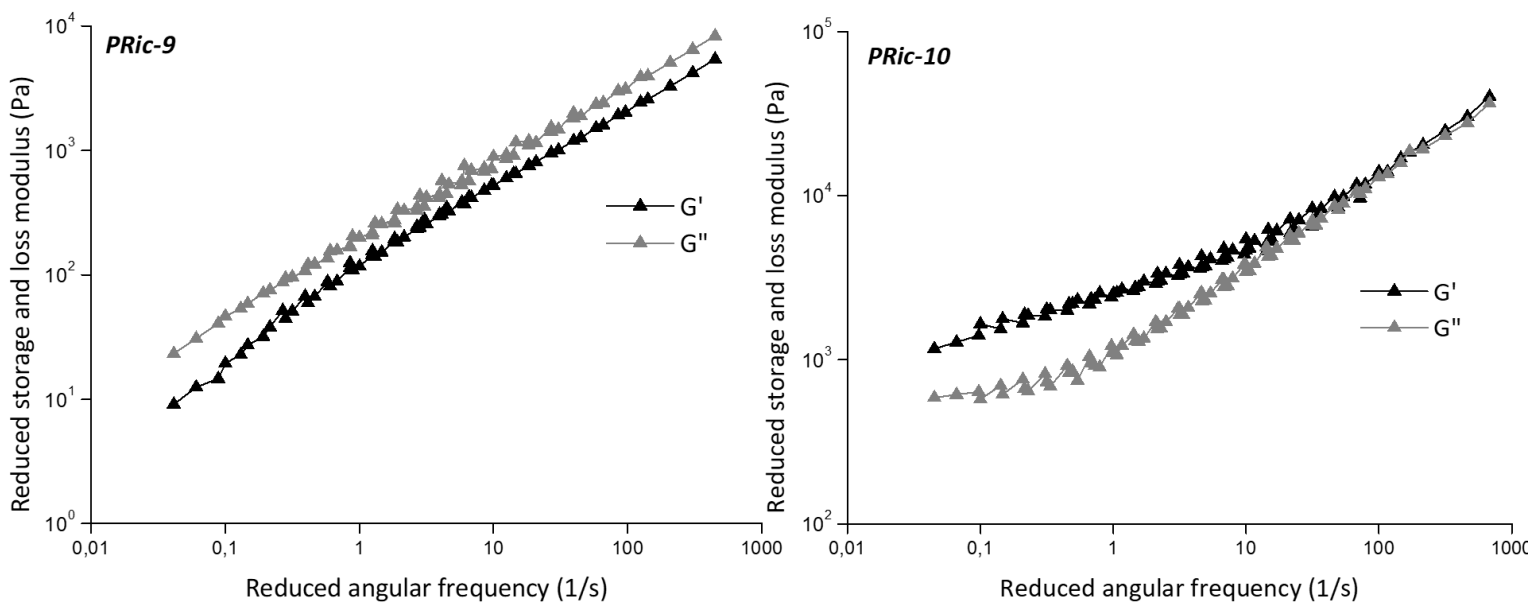

Figure SI-11: Master curves at $80^{\circ} \mathrm{C}$ of PRic- 9 and PRic- 10 samples. Reduced storage and loss modulus are expressed versus the reduced angular frequency

Table SI-3: Translation factor and activation energy obtained by TTS master curves at $-20^{\circ} \mathrm{C}$.

\begin{tabular}{|c|c|c|c|c|c|c|c|}
\hline & $\mathrm{T}\left({ }^{\circ} \mathrm{C}\right)$ & -30 & $-20 *$ & -10 & 0 & 20 & $\mathrm{Ea}\left(\mathrm{kJ} . \mathrm{mol}^{-1}\right)$ \\
\hline & $a_{T}$ & 5.911 & 1 & 0.173 & - & - & \\
\hline \multirow[t]{2}{*}{ PRic-6 } & $a_{T \text { calc }}$ & 6.256 & 1 & 0.184 & 0.038 & 0.002 & 93.72 \\
\hline & \%error & 5.62 & 0 & 5.67 & - & - & \\
\hline & $a_{T}$ & 2.592 & 1 & 0.350 & 0.143 & 0.042 & \\
\hline \multirow[t]{3}{*}{ PRic-7 } & $\boldsymbol{a}_{T \text { calc }}$ & 2.634 & 1 & 0.408 & 0.178 & 0.040 & 49.57 \\
\hline & \%error & 1.74 & 0 & 16.97 & 24.65 & 5.21 & \\
\hline & $a_{T}$ & 2.832 & 1 & 0.328 & 0.125 & 0.025 & \\
\hline \multirow[t]{3}{*}{ PRic-8 } & $a_{T \text { calc }}$ & 3.028 & 1 & 0.359 & 0.139 & 0.025 & 56.63 \\
\hline & \%error & 6.93 & 0 & 9.41 & 11.25 & 2.58 & \\
\hline & $a_{T}$ & 2.937 & 1 & 0.332 & 0.128 & 0.030 & \\
\hline \multirow[t]{3}{*}{ PRic-9 } & $a_{T \text { calc }}$ & 2.921 & 1 & 0.371 & 0.148 & 0.029 & 54.80 \\
\hline & \%error & 0.531 & 0 & -11.767 & -16.115 & 4.959 & \\
\hline & $a_{T}$ & 2.612 & 1 & 0.356 & 0.141 & 0.030 & \\
\hline \multirow[t]{2}{*}{ PRic-10 } & $\boldsymbol{a}_{T \text { calc }}$ & 2.846 & 1 & 0.380 & 0.155 & 0.031 & 53.47 \\
\hline & \%error & 8.957 & 0 & -6.996 & -10.430 & -4.458 & \\
\hline
\end{tabular}

$*$ : Reference temperature $-a_{T \text { calc }}$ are shift factors from computation using Arrhenius law 
Table SI-4: Translation factor and activation energy obtained by TTS master curves at $80^{\circ} \mathrm{C}$ as reference.

\begin{tabular}{|c|c|c|c|c|c|c|c|c|c|}
\hline & $\mathrm{T}\left({ }^{\circ} \mathrm{C}\right)$ & 20 & 40 & 60 & $80 *$ & 100 & 150 & 200 & Ea $\left(\mathrm{kJ} . \mathrm{mol}^{-1}\right)$ \\
\hline \multirow{3}{*}{ PRic-9 } & $a_{T}$ & 30.457 & 8.497 & 2.6867 & 1 & 0.4128 & - & - & \\
\hline & $a_{T \text { calc }}$ & 30.365 & 8.415 & 2.721 & 1 & 0.4091 & - & 0.0146 & 43.9 \\
\hline & \%error & 0.3013 & 0.953 & 1.2865 & 0 & 0.8885 & - & - & \\
\hline \multirow{3}{*}{ PRic-10 } & $a_{T}$ & 21.48 & 5.387 & 2.294 & 1 & 0.4504 & - & - & \\
\hline & $a_{T \text { calc }}$ & 20.061 & 6.498 & 2.410 & 1 & 0.456 & 0.089 & - & 42.98 \\
\hline & \%error & 6.608 & 20.62 & 5.045 & 0 & 1.243 & - & - & \\
\hline
\end{tabular}

*: Reference temperature $-a_{T \text { calc }}$ are shift factors from computation using Arrhenius law

\section{REFERENCE}

1 D. Van Krevelen and K. Nijenhuis, Properties of Polymers, Elsevier, 1992, vol. 16. 